\title{
Functional disability in community-dwelling elderly: the role of cataracts and contextual factors
}

\author{
Incapacidade funcional em idosos comunitários: \\ o papel da catarata e dos fatores contextuais
}

\author{
Larissa de Lima Borges ${ }^{[\mathrm{a}]}$, Fernanda Pains Vieira dos Santos ${ }^{[\mathrm{b}]}$, Valéria Pagotto ${ }^{[\mathrm{c}]}$, \\ Ruth Losada de Menezes ${ }^{[\mathrm{d}]}$
}

[a] MSc candidate, Universidade de Brasília (UnB), Programa de Pós-Graduação em Ciências e Tecnologias em Saúde, Ceilândia, DF - Brazil, e-mail: larissalima10@gmail.com

[b] MSc candidate, Universidade de Brasília (UnB), Programa de Pós-Graduação em Ciências e Tecnologias em Saúde, Ceilândia, DF - Brazil, e-mail: fepains@gmail.com

[c] PhD, Universidade Federal de Goiás (UFG), Faculdade de Enfermagem, Goiânia, GO - Brazil, e-mail: valeriapagotto@gmail.com

[d] PhD, professor, Universidade de Brasília (UnB), Programa de Pós-Graduação em Ciências e Tecnologias em Saúde, Ceilândia, DF - Brazil, e-mail: ruthlosada@uol.com.br

\begin{abstract}
Introduction: Cataract arises as a risk factor for functional disability in elderly Objective: To determine differences in functional capacity and contextual factors associated with it in elderly affected and not affected by cataract and association between disability and cataracts. Methods: A transversal-type observational study was carried out with 100 community elderly, divided into two groups: elderly affected (n = $50)$ and not affected by cataracts $(n=50)$. It was evaluated: activities of daily living (ADL) - Katz Index -, instrumental activities of daily living (IADL) - Lawton scale - and mobility - Short Physical Performance Battery. Functional disability was detected when the elderly were dependent or semi-dependent for one or more IADL or ADL and/or when they presented any difficulty in mobility. Data analysis included absolute and relative frequencies, Chi-squared or Fisher's exact tests $(\mathrm{p}<0.05)$ and Poisson regression. Results: No statistically significant associations were observed between IADL, ADL or mobility disability and cataracts.
\end{abstract}


A statistically significant difference was observed between the disabled elderly affected and not affected by cataract according to contextual factors for ADL regarding age $(p=0.037)$ and comorbidity $(p=0.037)$, for mobility regarding the practice of physical activity $(p=0.013)$, and for IADL $(p=0.001)$, ADL ( $p=0.001)$ and mobility $(p=0.013)$ regarding the self-reporting of eyesight problems. Conclusions: Besides cataracts, physical inactivity, comorbidity and functional aging itself are contributing factors to the process of disability in elderly, so, the physiotherapy is essential both to prevent as to reverse this process.

Keywords: Aged. Functional ability. Lens opacity. Mobility limitations.

\section{Resumo}

Introdução: Catarata surge como fator de risco para a incapacidade funcional em idosos. Objetivos: Determinar diferenças na capacidade funcional e nos fatores contextuais a ela associados em idosos com e sem catarata e associação entre incapacidade funcional e catarata. Métodos: Estudo observacional transversal, realizado com uma amostra de 100 idosos comunitários, divididos em dois grupos: idosos com catarata $(n=50)$ e idosos sem catarata ( $n=50)$. Foram avaliadas: atividades de vida diária (AVD) - Índice de Katz -, atividades instrumentais de vida diária (AIVD) - Escala de Lawton - e mobilidade - Short Physical Pherformance Battery. Incapacidade funcional foi detectada quando os idosos apresentassem dependência ou semi-dependência para uma ou mais AVD ou AIVD e/ou qualquer dificuldade na mobilidade. As análises dos dados incluíram frequência absoluta e relativa, testes Qui quadrado ou Exato de Fisther $(p<0.05)$ e análise regressiva de Poisson. Resultados: Não houve associação estatisticamente significativa entre AIVD, AVD ou mobilidade e ter catarata. Diferença estatisticamente significativa entre os idosos incapacitados de G1 e G2 conforme os fatores contextuais ocorreram para faixa etária ( $p=0.037)$, comorbidade $(p=0.037)$ e incapacidade para AVD; prática de atividade física ( $p=$ 0.013 ) e incapacidade para mobilidade e autorrelato de dificuldade de enxergar e incapacidade para AIVD ( $p=$ 0.001), AVD ( $p=0.001)$ e mobilidade ( $p=0.013)$. Conclusões: Além de catarata, inatividade física, comorbidade e o próprio envelhecimento funcional são fatores contribuintes para o processo de incapacidade em idosos, assim, a fisioterapia é essencial tanto para prevenir como para reverter este processo.

Palavras-chave: Idoso. Catarata. Atividades cotidianas. Limitação da mobilidade.

The International Classification of Functioning, Disability and Health (ICF) of the World Health Organization (WHO) adopts a biopsychosocial approach in which the disability process is affected by health conditions that include components such as body functions/structures, activity and participation, and contextual factors (environmental and personal) (1).

However, for the elderly, the definition generally used for functional disability is restricted to the self-reporting difficulty or need help of this to carry out: i) Activities of Daily Living (ADL) - such as feeding, bathing, dressing, transferring, among others; ii) Instrumental Activities of Daily Living (IADL) - such as preparing meals, shopping, use of transportation services, taking medication, among others; and iii) tasks related to mobility (2), being the latter defined by ICF within the activity and participation component (1). This study adopted this theoretical definition, and in a complementary way, it considered yet the contextual factors as proposed by the ICF.

Research on the functional disability of the elderly is paramount once that its prevalence and incidence tend to increase with age $(3,4)$, and its presence can be the first sign of an illness or complications in the elderly. Besides, it is associated with adverse outcomes such as loss of autonomy, institutionalization, death $(5,6)$, reduction in general and disability-free life expectancy, and increase of disabled life expectancy $(7,8,9)$.

Among the multiple gender-independent risk factors for functional disabilities (IADL, ADL, and mobility) in the elderly, a 2009 systematic review pointed the visual deficiency (10). Visual deficiencies of different causes were associated with social isolation, solitude and depression, gait abnormalities, decrease in functional capacity to carry out activities directly 
related to vision and also instrumental activities of daily living $(11,12,13,14)$.

Specifically about cataracts, their impact on the functional capacity of the elderly represents a gap in scientific literature, although they are the greatest cause of blindness and visual impairments in individuals over the age of 50 in developing countries, and contribute with more than $90 \%$ of the total of years lived with disability (15). In Brazil, cataract is the ophthalmologic illness that appears as the main cause of treatable visual deficiencies (54.9\%) and blindness (30.0\%) (16).

In the light of the above, the present study aims at describing and comparing contextual factors (sociodemographic and general health characteristics) between elderly affected and not affected by cataracts, estimating the prevalence of functional disabilities for ADL, IADL, and mobility, and it association with cataracts and, verifying the differences between the disabled elderly with and without cataracts, according to contextual factors. The initial hypothesis is that cataract and contextual factors are conditions that predispose the elderly to functional disability.

\section{Methods}

Study design and sample

A transversal-type observational study is presented herein, carried out in the Federal District, Brazil, part of a wider project entitled Impact of cataract surgery on the occurrence of falls and multidimensional aspects of health: a longitudinal study in the elderly of the Federal District.

The convenience sample was constituted by elderly selected from two different locations according to the presence or absence of cataracts and that were evaluated between December/2011 and December/2012. The elderly with bilateral cataracts were recruited from the cataract surgery schedules from the two only hospitals of the Federal District Health State Office that are qualified for such procedure: Ophthalmology Departments of the Hospital de Base (HB) and the Regional Hospital of Taguatinga (RHT). The elderly not affected by cataract (selfreport) were recruited from the Regional Health Centers of Ceilândia and Sobradinho.
Other inclusion criteria adopted for the subjects affected and not affected by cataracts were being community-dwelling elderly ( $\geq 60$ years) of both genders and capable of walking. In total, 138 elderly were evaluated and of these, 100 were included in the sample, 50 elderly patients with bilateral cataracts and surgical indication (group 1 - G1) and 50 subjects without cataracts (group 2 - G2).

Exclusion criteria were adopted that could have interfered in the performance of physical tests and/or interviews or acted as confounders for the outcome analyzed: clinical diagnosis or acute cognitive deficit suggesting dementia (MMSE < 17) $(\mathrm{n}=6)$, Parkinson Disease ( $n=0)$, Encephalic Vascular Accident ( $n=1)$, surgical correction of cataract in one eye $(n=14)$, and positive diabetes self-reporting for over five years ( $\mathrm{n}=17$ ).

\section{Ethics and procedures}

This research was approved by the Ethics Committee of the Health Sciences Research and Teaching Faculty (FEPECS) (0153/2011) and all participants signed free informed consent form in accordance with rules established by resolution 196/96 of the Conselho Nacional de Saúde (National Health Council) for research involving humans.

After approval by the ethics committee, selection of participants was carried out in the previously mentioned sites through pamphlets, posters and further telephone contact for clarification on research aspects, invitation to participate and scheduling of assessment at UnB - Ceilândia Campus. The evaluators received training regarding the instruments utilized. The assessment of each participant lasted approximately 60 minutes and each senior was evaluated only once.

\section{Instruments}

\section{Mini Mental State Examination (MMSE)}

The MMSE, elaborated by Folstein et al. (17), was employed to exclude the elderly that presented acute cognitive deficit suggestive of dementia (cutoff score: 17 points) (18). The test is constituted by 30 questions and each question can be scored as 0 (error) 
or 1 (correct) with the total score varying between 0 to a maximum of 30 points (17).

\section{Semi-structured interview}

In this interview the following contextual factors were investigated: sociodemographic and general health characteristics. The sociodemographic data collected were gender, age, marital status, education level, retirement pension and family support.

General health data were analyzed through the self-reporting of medical history and number of illnesses, number of medications being taken, level of physical activity, and autoperception of eyesight capacity even with the aid of glasses or lenses (no difficulty, low or high degree of difficulty).

\section{Short Physical Performance Battery (SPPB)}

The SPPB (19) was developed to assess mobility through direct observation by an examiner and, in 2007, was adapted for Brazil by Nakano (20). SPPB is constituted by five tests that evaluate, respectively: static balance, gait speed and lower extremity muscle strength. The total score vary from zero (worst performance) to 12 points (best performance) (20). This study considered the SPPB classification proposed by Guralnik et al.(21) with the following adaptations: bad, low or moderate performance (0-9) and good performance (10-12), with a mobility disability being determined by any difficulty in executing the tasks, i.e., bad, low or moderate performances.

\section{Katz Index (KI) and Lawton Scale (LS)}

For ADL the Katz Index (KI) was used (22), which measures independency or dependency for six activities, which are related and hierarchically organized: bathing, dressing, toileting, transferring, urinary and fecal continence, and feeding (23). This study standardized the following categories: independent or dependent for one or more ADL, being the latter an indicator of disability.

For IADL the Lawton Scale (LS) was utilized, which covers nine activities (use of telephone, shopping, use of transportation, housekeeping, manual labor, laundry, food preparation, taking medication and ability to handle finances) (24). For each activity the elderly could have been considered independent, semi-dependent or dependent (24). This study standardized the following categories: independent and dependent/semi-dependent for one or more IADL, being the latter an indicator of disability.

\section{Statistical analysis}

Data were analyzed by software STATA 12.0 . Initially, a descriptive and comparative analysis was carried out for the contextual factors between groups G1 and G2 through absolute and relative frequencies. The Chi-squared or Fisher's Exact tests were utilized to compare the proportions, considering $\mathrm{p}<$ 0.05 . The prevalence of outcomes was then estimated (functional disability for ADL, IADL and mobility) in the general sample and according to groups G1 and G2. A Simple Poisson Regression was used to analyze the association between outcomes of disability and the independent variable cataracts. The magnitude of the association was estimated by the Prevalence Ratio (PR), considering the 5\% significance level $(\mathrm{p}<0.05)$ and the corresponding 95\% confidence intervals. The prevalence of each one of the outcomes, according to groups G1 and G2, was also estimated for the contextual factors and the differences were analyzed by the chi-squared or Fisher's exact texts $(\mathrm{p}<0.05)$.

\section{Results}

Regarding age groups, the majority of the elderly of G1 and G2 belonged, respectively, to the oldest age group (over 70 years old) and to the youngest age group (between 60 and 69 years of age), with a significant statistical difference $(p=0.046)$. In general health characteristics, a statistically significant difference was verified between groups regarding the presence of comorbidity ( $p=0.001)$, physical inactivity ( $p=0.014$ ), and autoperception of eyesight as with some difficulty $(\mathrm{p}=0.000)$, with a higher prevalence in the elderly that suffered from cataracts (Table 1).

Table 2 presents the prevalence of functional disability and its association with cataracts. The highest disability prevalence occurred for IADL $(57.0 \%)$, followed by ADL (42.0\%), and mobility (24.0\%) in the general sample. No statistically significant 
associations were observed between IADL disability (RP $=1.47$ CI95\%:0.96; 1.95), ADL disability (RP $=1.37 \mathrm{CI} 95 \%: 0.91 ; 2.37)$ or mobility disability (RP $=1.4$ CI95\%:0.68; 2.85 ) and cataracts, although the highest prevalence of disability occurred in the elderly that suffered from cataract $(50.0 \%$ for ADL, $66.0 \%$ for IADL, and $28.0 \%$ for mobility). ADL dependency was restricted to urinary continence, with a higher prevalence in the elderly that suffered from cataracts $(p=0.315)$. Regarding mobility, the majority of the elderly from both groups presented good performance and, among the $24.0 \%$ that presented some difficulty, the greater part suffered from cataracts.

In Tables 3 and 4, the prevalence of functional disability (ADL, IADL, and mobility) was estimated according to contextual factors in the elderly of groups G1 and G2, and the differences were analyzed. A statistically significant difference was observed between the (i) ADL-disabled elderly of groups G1 and G2 regarding age group ( $p=0.037)$ and comorbidity ( $p=0.037)$, with the highest prevalence of this disability found in the elderly over the age of 70 and suffering from five or more illnesses from G1; (ii) mobility-disabled elderly of groups G1 and $\mathrm{G} 2$ regarding the practice of physical activity ( $\mathrm{p}$ $=0.013$ ), with the highest prevalence among sedentary elderly from G1.

Figure 1 highlights the statistically significant differences between disabled elderly of groups G1 and G2 for ADL ( $p=0.001)$, IADL ( $=0.001)$, and morbidity $(p=0.013)$, regarding the self-report of eyesight difficulties. Figure 1 also depicts the fact that in G1, the prevalence of disability was higher for those that reported low or high degrees of eyesight difficulties, while in G2 the highest prevalence occurred in those who did not report vision difficulties.

Table 1 - Contextual factors for the elderly from Gl and G2

\begin{tabular}{|c|c|c|c|}
\hline \multirow{2}{*}{ Variable } & G1 & G2 & \multirow{2}{*}{$p$} \\
\hline & n (\%) & n (\%) & \\
\hline Gender & & & $0.155^{\star}$ \\
\hline Female & $26(52.0)$ & $33(66.0)$ & \\
\hline Male & $24(48.0)$ & $17(34.0)$ & \\
\hline Age group (years) & & & $0.046^{*}$ \\
\hline $60-69$ & $20(40.0)$ & $30(60.0)$ & \\
\hline$\geq 70$ & $30(60.0)$ & $20(40.0)$ & \\
\hline Education level & & & $0.820^{*}$ \\
\hline None & $12(24.0)$ & $11(22.0)$ & \\
\hline$\leq 4$ years & $22(44.0)$ & $20(40.0)$ & \\
\hline$>4$ years & $16(32.0)$ & $19(38.0)$ & \\
\hline Self-reporting: eyesight capacity & & & $0.000^{*}$ \\
\hline No difficulties & $4(8.0)$ & $32(64.0)$ & \\
\hline Low level of difficulty & $22(44.0)$ & $10(20.0)$ & \\
\hline High level of difficulty & $24(48.0)$ & $8(16.0)$ & \\
\hline \multicolumn{4}{|l|}{ Self-referred morbidities } \\
\hline Systolic Hypertension & $27(54.0)$ & $27(54.0)$ & $1.000^{*}$ \\
\hline Arthritis/arthrosis & $18(36.0)$ & $15(30.0)$ & $0.319^{*}$ \\
\hline Heart disease & $14(28.0)$ & $15(30.0)$ & $0.826^{*}$ \\
\hline Osteoporosis & $9(18.0)$ & $10(20.0)$ & $0.799^{*}$ \\
\hline
\end{tabular}


Table 1 - Contextual factors for the elderly from G1 and G2

(Conclusion)

\begin{tabular}{|c|c|c|c|}
\hline \multirow{2}{*}{ Variable } & G1 & G2 & \multirow{2}{*}{$p$} \\
\hline & n (\%) & n (\%) & \\
\hline Depression & $14(28.0)$ & $15(30.0)$ & $0.584^{*}$ \\
\hline Diabetes $<5$ anos & $7(14.0)$ & $3(6.0)$ & $0.001^{* *}$ \\
\hline Comorbidity & & & $0.015^{*}$ \\
\hline $0-2$ & $14(28.0)$ & $27(54.0)$ & \\
\hline 3 to 4 & $21(42.0)$ & $17(34.0)$ & \\
\hline$\geq 5$ & $15(30.0)$ & $6(12.0)$ & \\
\hline Regular physical activity & & & $0.014^{*}$ \\
\hline Yes & $24(48.0)$ & $36(68.0)$ & \\
\hline No & $26(52.0)$ & $14(28.0)$ & \\
\hline
\end{tabular}

Note: G1: elderly with cataract; G2: elderly without cataract. ${ }^{\star}$ Chi-squared $(p<0.05){ }^{* *}$ Fisher's exact $(p<0.05)$ tests.

Source: Research data.

Table 2 - Prevalence of functional disability (ADL, IADL, and mobility) in the general sample and in the elderly with and without cataract

\begin{tabular}{|c|c|c|c|c|}
\hline \multirow{2}{*}{ Groups } & \multicolumn{4}{|c|}{ Functional disability n (\%) } \\
\hline & \multicolumn{2}{|c|}{$A D L$} & \multirow[t]{3}{*}{ RP (IC95\%) } & \multirow[t]{3}{*}{$p$} \\
\hline & Dependent & Independent & & \\
\hline & $(n=42)$ & $(n=58)$ & & \\
\hline General sample & $42(42.0)$ & $58(58.0)$ & - & \\
\hline With cataract (G1) & $25(50.0)$ & $25(50.0)$ & $1.47(0.91-2.37)$ & 0.114 \\
\hline \multirow[t]{4}{*}{ No cataract (G2) } & $17(34.0)$ & $33(66.0)$ & 1.00 & \\
\hline & \multicolumn{2}{|c|}{ IADL } & RP (IC95\%) & $p$ \\
\hline & Dependent & Independent & & \\
\hline & $(n=57)$ & $(n=43)$ & & \\
\hline General sample & $57(57.0)$ & $43(43.0)$ & - & \\
\hline With cataract (G1) & $33(66.0)$ & $17(34.0)$ & $1.37(0.96-1.95)$ & 0.076 \\
\hline \multirow[t]{4}{*}{ No cataract (G2) } & $24(48.0)$ & $26(52.0)$ & 1.00 & \\
\hline & \multicolumn{2}{|c|}{ Mobility } & RP (IC95\%) & $p$ \\
\hline & Bad to moderate & Good & & \\
\hline & $(n=24)$ & $(n=76)$ & & \\
\hline General sample & $24(24.0)$ & $76(76.0)$ & - & \\
\hline With cataract (G1) & $14(28.0)$ & $36(72.0)$ & $1.40(0.68-2.85)$ & 0.356 \\
\hline No cataract (G2) & $10(20.0)$ & $40(80.0)$ & 1.00 & \\
\hline
\end{tabular}

Note: Chi-squared test $(\mathrm{p}<0.05)$.

Source: Research data. 


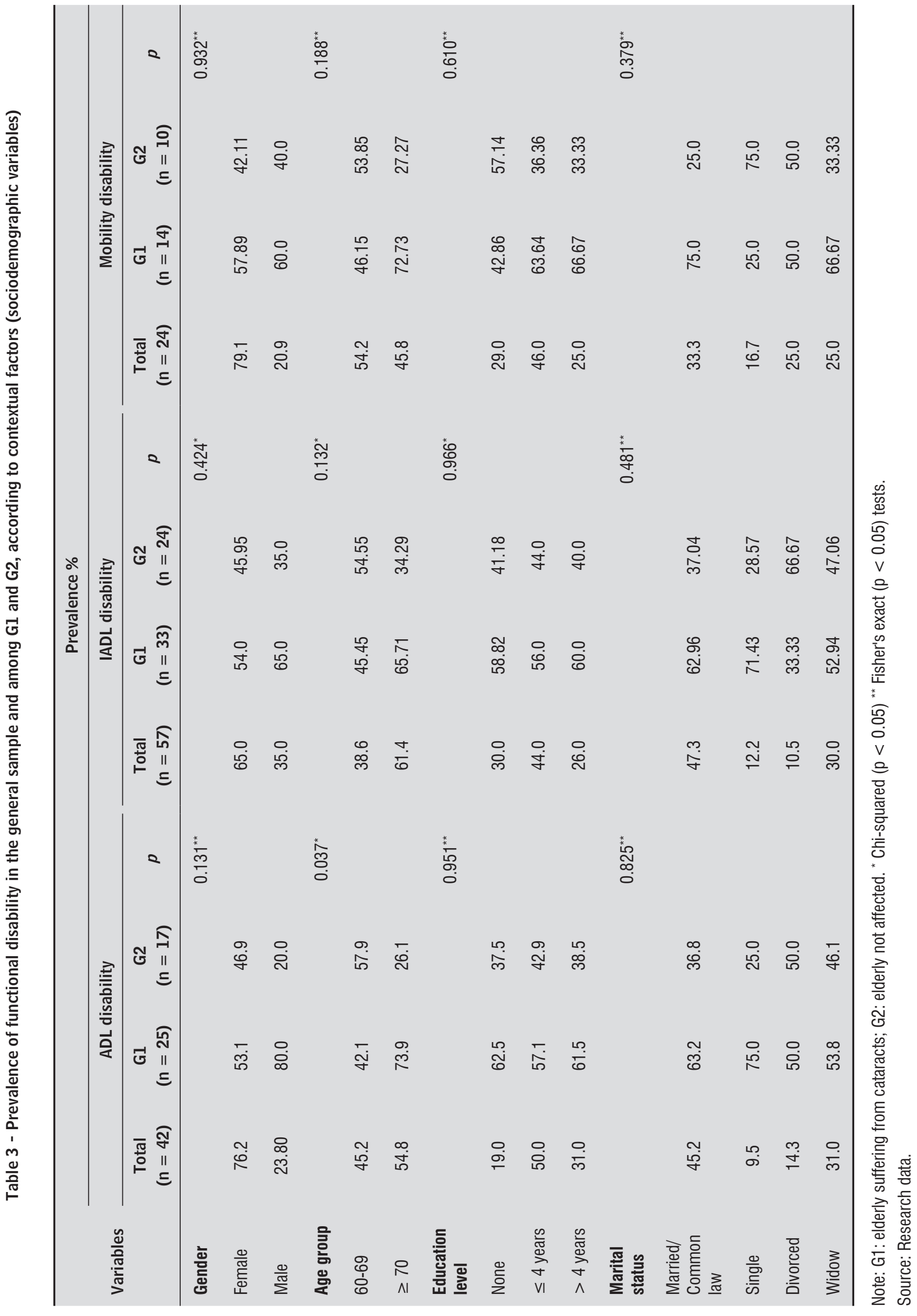




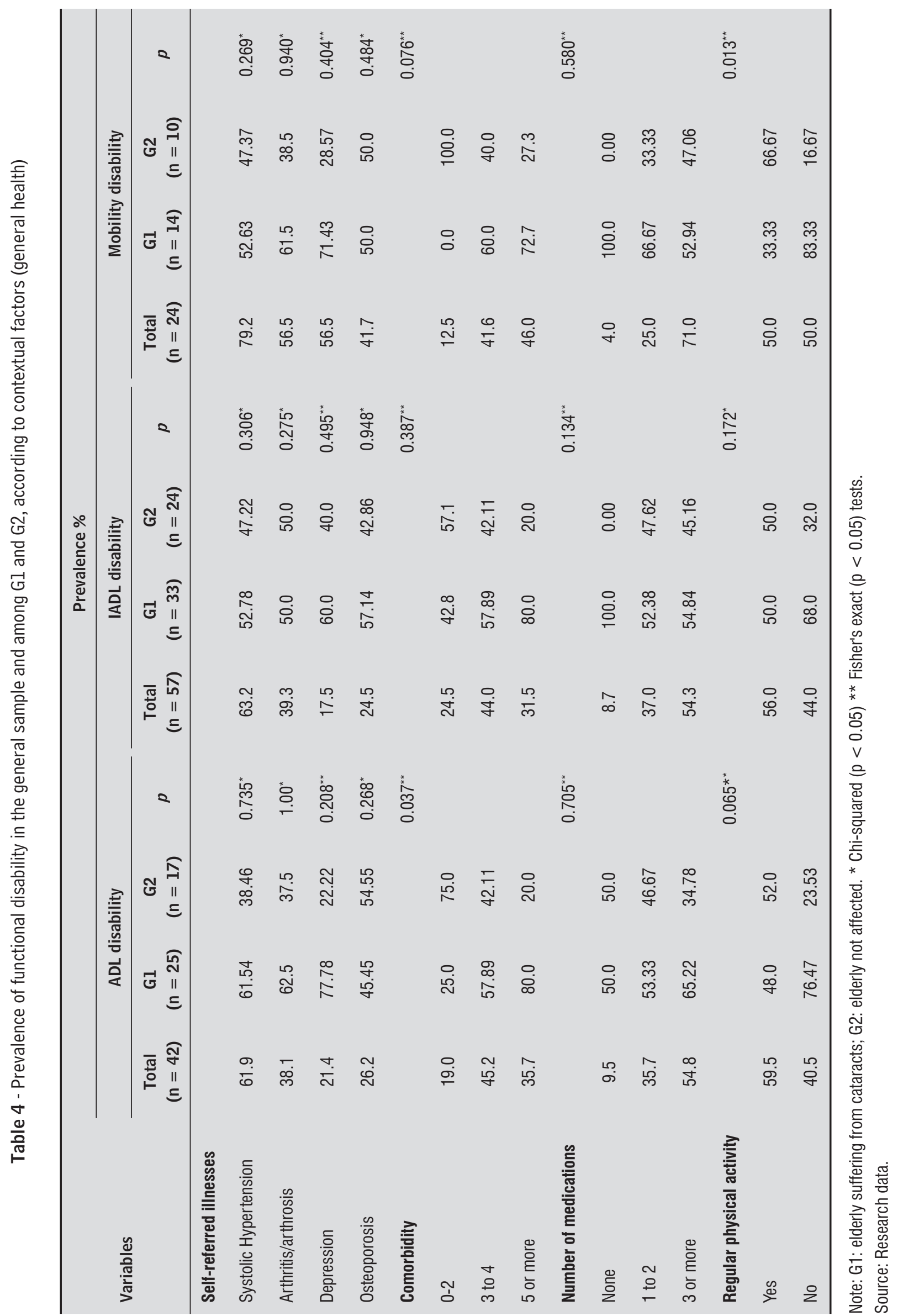




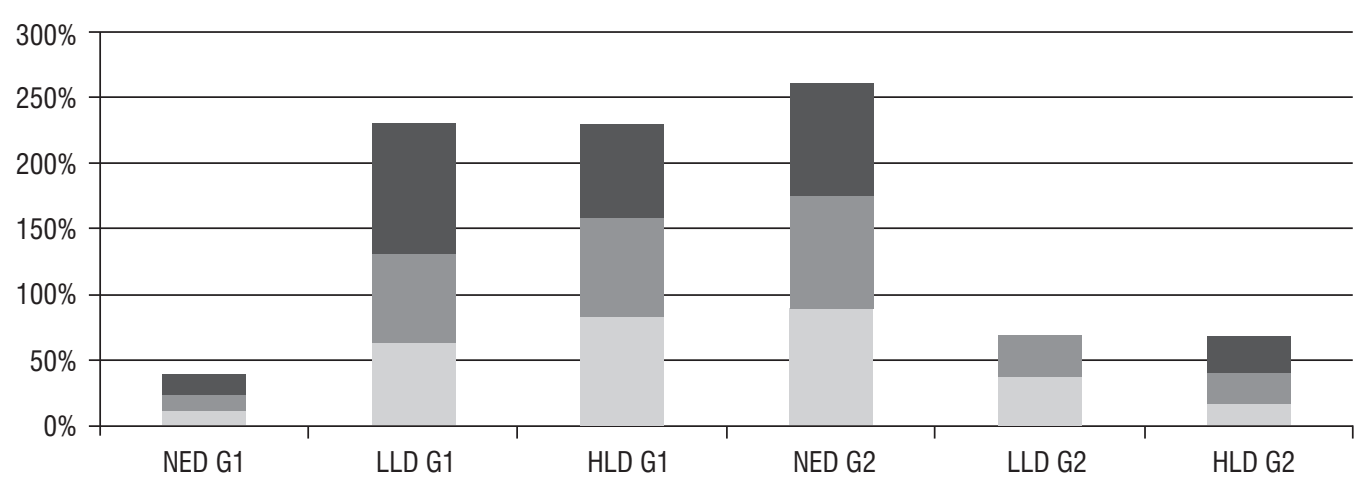

Mobility disability

IADL disability

ADL disability

Figure 1 - Prevalence of functional disability according to the self-report of eyesight difficulties in G1 and G2 Note: NED: No eyesight difficulties; LLD: Low level of eyesight difficulty; HLD: High level of eyesight difficulty.

Source: Research data.

\section{Discussion}

Although no statistically significant associations were observed between functional disability and cataracts, the elderly that suffered from cataracts presented higher prevalence of functional disability for ADL, IADL, and mobility, compared to the elderly not affected by cataracts. The statistically significant differences between the disabled elderly of G1 and G2 according to the contextual factors occurred for age, comorbidity, and incapacity to execute ADL, practice of physical activity and mobility disability, self-reporting of eyesight difficulties and incapacity to execute ADL, IADL, and mobility. Therefore, it was observed that the cataract, unlike the contextual factors such as age, comorbidity, and physical inactivity, did not predispose the elderly to functional disability.

A trend was confirmed herein: the older participants belonged to the group of those suffering from cataracts, as observed in other research $(25,26)$. The study by Furtado et al. (26) demonstrated an increase in the prevalence of cataracts in Brazil, from 1.5\% ( $\geq 50$ years) to $8 \%$ in those over the age of 80 (25) the aging process leads to increases in the density and oxidative stress of crystalline cells, resulting in opacification $(27,28)$.

Besides presenting more advanced age, the elderly affected by cataracts complained about greater vision difficulties, higher number of illnesses, and sedentarism. The scientific literature demonstrates that the elderly who suffer from multiple illnesses, generally, exercise less (29) and, besides, the elderly with visual deficiencies tend to isolate themselves, be depressive, and present functional compromises (25), interfering therefore in the levels of physical activity.

The prevalences of functional disability in general sample for ADL, IADL and mobility were equivalents to the rates detected by Millán-Calenti et al.(30) and by Parahyba and Simões (31), and it was observed in this study too that the highest prevalence occurred for IADL, followed by ADL and mobility. This fact is justified by the hierarchy of losses in which more complex activities (IADL) are impaired in initial stages, and simpler activities (ADL) are affected in later stages of the disability process. Mobility loss is considered as an intermediate loss (32). On an opposite direction, the elevated percentage of independent elderly is highlighted in the general sample for ADL (58.0\%), IADL (43.0\%) and mobility (76.0\%), which also corroborates with previous studies $(30,31,33$, $34,35,36$ ) and confirms the necessity of preventing functional disability and its adverse effects.

For ADL, the study by Del Duca, Silva \& Hallal (34) also observed non-accumulated disability for ADL, with higher prevalence for urinary continence $(21.3 \%)$. The elderly suffering from cataracts, 
compared to those not affected, presented higher prevalence (50.0\%) in ADL disability, in this case, for continence. It is well-known that visual deficiencies interfere with gait, resulting in a slower, and unstable gait in the elderly (13), which can increase the traveling time to the washroom and therefore lead to involuntary losses of urine.

In IADL disability, the elderly suffering from cataracts present higher prevalence (66.0\%), compared to the elderly not affected. Studies carried out in Australia (37) and in Brazil (14) detected that that the highest constraints presented for individuals affected by visual deficiencies were related to instrumental activities such as reading, use of telephone, washiron clothes, execute manual labor, take medicine and prepare meals.

Regarding mobility disability, the elderly affected by cataracts presented higher prevalence $(28.0 \%)$ when compared to the elderly not affected, as associations between visual deficiency in the elderly and slower gait (13) and postural instability (38) have already been demonstrated, which also interferes in the performance of SPPB tests.

There was a statistically significant difference between the mobility-disabled elderly of G1 and G2 regarding the physical exercise levels, with an elevated prevalence of sedentarism in G1 (83.33\%). Sedentarism is related to the loss of muscle strength in inferior limb extensors, to deficiencies in physical abilities measured by SPPB, as well as to losses in IADL and ADL (32). A recent meta-analysis (39) points out that regular physical activity is the most effective strategy to prevent, reduce worsening, and slower functional aging processes, as well as to maintain independency in the elderly and reduce health costs.

A statistically significant difference was detected between ADL-disabled elderly from G1 and G2 regarding age and comorbidity, with the highest prevalences among the older participants affected by cataracts and suffering from five or more illnesses. Recent transversal $(30,35)$ and longitudinal studies $(36,40)$ demonstrated the aging process as a risk factor for the beginning or worsening of the functional disability scenario, both for ADL and IADL, as well as comorbidity $(10,30,33,36)$ and visual deficiency $(11$, 14 ), which are additional risk factors in this process.

Regarding the self-reporting of eyesight difficulties and functional disability, the study by Lee et al. (41) demonstrated statistically significant associations between visual symptoms and mental and physical health components, but the same did not occur when considering ophthalmologic disease diagnosis (41). This reinforces the importance of considering not only the clinical diagnosis, but also the self-report of the patient regarding eyesight difficulties and its interference in daily activities. Figure 1 confirms the multifactorial nature of the functional disability process in the elderly $(6,10,30,31,33,36$, 40 ), once the majority of disabled elderly in G2 did not complain about vision difficulties, i.e., not only visual deficiency, but other risk factors are involved in the process of functional losses.

At this point, some considerations on this study must be made. The transversal design emerges as a possible limitation of this study as it does not allow for the establishment of a cause-effect relationship. Other limitations to be considered are the following: convenience sample constituted by a small number of participants and the non-identification and consecutive exclusion of other uncorrected ophthalmologic diseases that could have masked cataracts.

This study highlighted that the higher prevalence of functional disability (IADL, ADL and mobility) occurred in the elderly that suffered from cataracts, although the association between functional disability and cataracts was statistically non-significant. Statistically significant differences were obtained between the disabled elderly of groups G1 and G2 regarding contextual factors as follows: for ADL regarding age and comorbidity, for mobility regarding the practice of physical activity, and for IADL, ADL and mobility regarding the self-reporting of eyesight problems.

\section{Acknowledgments}

Secretaria de Estado da Saúde do Distrito Federal (SES/DF).

Conselho Nacional de Desenvolvimeneto Científico e Tecnológico (CNPq) funded this study in the framework of project 480434/2011-5.

\section{References}

1. Sampaio RF, Luz MT. Funcionalidade e incapacidade humana: explorando o escopo da classificação internacional da Organização Mundial da Saúde. Cad Saúde Pública 2009;25(3):475-83. 
2. Alves LC, Machado CJ. Conceituando e mensurando a incapacidade funcional da população idosa: uma revisão de literatura. Ciên Saúde Colet. 2008; 13(4):1199-207.

3. Wolinsky F, Bentler S, Hockenberry J, Jones M, Obrizan $\mathrm{M}$, Weigel P, et al. Long-term declines in ADLs, IADLs, and mobility among older Medicare beneficiaries. BMC Geriatr. 2011;11(1):43.

4. Palacios-Ceña D, Jiménez-García R, Hernández-Barrera V, Alonso-Blanco C, Carrasco-Garrido P, Fernándezde-las-Peñas C. Has the prevalence of disability increased over the past decade (2000-2007) in elderly people? A Spanish population-based survey. J Am Med Dir Assoc. 2012;13(2):136-42.

5. Bravell ME, Berg S, Malmberg B. Health, functional capacity, formal care, and survival in the oldest old: a longitudinal study. Arch Gerontol Geriatr. 2008; 46(1):1-14.

6. Marengoni A, Von Strauss E, Rizzuto D, Winblad B, Fratiglioni L. The impact of chronic multimorbidity and disability on functional decline and survival in elderly persons. A community-based, longitudinal study. J Intern Med. 2009;265(2):288-95.

7. Camargos MCS, Machado CJ, Rodrigues RN. Life expectancy among elderly Brazilians in 2003 according to different levels of functional disability. Cad Saúde Pública. 2008;24(4):845-52.

8. Keeler E, Guralnik JM, Tian H, Wallace RB, Reuben DB. The impact of functional status on life expectancy in older persons. J Gerontol A Biol Sci Med Sci. 2010; 65(7):727-33.

9. Landi F, Liperotia R, Russoa A, Capoluongo E, Barillaro C, Pahor M, et al. Disability, more than multimorbidity, was predictive of mortality among older persons aged 80 years and older. J Clin Epidemiol. 2010;63(7):752-9.

10. Rodrigues MAP, Facchini LA, Thumé E, Maia F. Gender and incidence of functional disability in the elderly: a systematic review. Cad Saúde Pública 2009;25(Suppl 3): S464-76.

11. Gonzalez Simon E, Coco Martin MB, Del Alamo Martin MT, de Lazaro Yague JA, Cuadrado Asensio R, Coco Martin RM. The impact of the dependency law in low vision patients. Arch Soc Esp Oftalmol. 2007; 82(7):393-4.
12. Freeman EE, Gresset J, Djafari F, Aubin M, Couture S, Bruen R, et al. Cataract-related vision loss and depression in a cohort of patients awaiting cataract surgery. Can J Ophthalmol. 2009;44(2):171-6.

13. Helbostad JL, Vereijken B, Hesseberg K, Sletvold O. Altered vision destabilizes gait in older persons. Gait Posture. 2009;30(2):233-8.

14. de Melo Borges S, Cintra FA. Relação entre acuidade visual e atividades instrumentais de vida diária em idosos em seguimento ambulatorial. Rev Bras Oftalmol. 2010;69(3):146-51.

15. Rao GN, Khanna R, Payal A. The global burden of cataract. Curr Opin Ophthalmol. 2011;22(1):4-9.

16. Salomão SR, Cinoto RW, Berezovsky A, Araújo-Filho A, Mitsuhiro M, Mendieta L, et al. Prevalence and Causes of vision impairment and blindness in older adults in Brazil: the São Paulo eye study. Ophthalmic Epidemiol. 2008;15(3):167-75.

17. Folstein MF, Folstein SE, McHugh PR. "Mini-mental state": a practical method for grading the cognitive state of patients for the clinician. J Psychiatr Res. 1975; 12(3):189-98.

18. Silva SLA, Silva VG, Máximo LS, Dias JMD, Dias RC. Comparação entre diferentes pontos de corte na classificação do perfil de fragilidade de idosos comunitários. Geriatr Gerontol. 2011;5(3):130-5.

19. Guralnik JM, Simonsick EM, Ferrucci L, Glynn R, Berkman L, Blazer D, et al. A short physical performance battery assessing lower extremity function: association with self-reported disability and prediction of mortality and nursing home admission. J Gerontol. 1994;49(2):85-94.

20. Nakano MM. Versão Brasileira da Short Physical Performance Battery - SPPB: adaptação cultural e estudo da confiabilidade (dissertação). Campinas: Universidade Estadual de Campinas; 2007.

21. Guralnik JM, Ferrucci L, Pieper CF, Leveille SG, Markides KS, Ostir GV. Lower extremity function and subsequent disability: consistency across studies, predictive models, and value of gait speed alone compared with the short physical performance battery. J Gerontol A Biol Sci Med Sci. 2000;55(4):221-31. 
22. Katz S, Ford AB, Moskowitz RW, Jackson BA, Jaffe MW. Studies of illness in the aged. The index of adl: a standardized measure of biological and psychosocial function. JAMA. 1963;185:914-9.

23. Lino VTS, Pereira SRM, Camacho LAB, Ribeiro Filho ST, Buksman S. Adaptação transcultural da Escala de Independência em Atividades da Vida Diária (Escala de Katz). Cad Saúde Pública. 2008;24(1):103-12.

24. Lawton MP, Brody EM. Assessment of older people: self-maintaining and instrumental activities of daily living. Gerontologist. 1969;9(3):179-86.

25. Luiz LC, Rebelatto JR, Coimbra AM, Ricci NA. Associação entre déficit visual e aspectos clínico-funcionais em idosos da comunidade. Rev Bras Fisioter. 2009;13(5):444-50.

26. Furtado JM, Lansingh VC, Carter MJ, Milanese M, Pena B, Chersi H, et al. Causes of blindness and visual impairment in Latin America. Surv Ophthalmol. 2012;57(2):149-77.

27. Ho M-C, Peng Y-J, Chen S-J, Chiou S-H. Senile cataracts and oxidative stress. JCGG. 2010;1(1):17-21.

28. Pathai S, Gilbert CE, Lawn SD, Weiss H, Peto T, Cook C, et al. Assessment of candidate ocular biomarkers of ageing in a South African adult population: relationship with chronological age and systemic biomarkers. Mech Ageing Dev.. 2013; 134(7-8): 338-45.

29. Harris TJ, Owen CG, Victor CR, Adams R, Ekelund U, Cook DG. A comparison of questionnaire, accelerometer, and pedometer: measures in older people. Med Sci Sports Exerc. 2009;41(7):1392-402.

30. Millán-Calenti JC, Tubío J, Pita-Fernández S, GonzálezAbraldes I, Lorenzo T, Fernández-Arruty T,et al. Prevalence of functional disability in activities of daily living (ADL), instrumental activities of daily living (IADL) and associated factors, as predictors of morbidity and mortality. Arch Gerontol Geriatr. 2010;50(3):306-10.

31. Parahyba MI, Simões CCS. A prevalência de incapacidade funcional em idosos no Brasil. Ciên Saúde Colet. 2006;11(4):967-74.

32. den Ouden MEM, Schuurmans MJ, Brand JS, Arts IEMA, Mueller-Schotte S, van der Schouw YT. Physical functioning is related to both an impaired physical ability and ADL disability: a ten year follow-up study in middle-aged and older persons. Maturitas. 2013;74(1):89-94.
33. Giacomin KC, Peixoto SV, Uchoa E, Lima-Costa MF Estudo de base populacional dos fatores associados à incapacidade funcional entre idosos na Região Metropolitana de Belo Horizonte, Minas Gerais, Brasil. Cad Saúde Pública. 2008;24(6):1260-70.

34. Del Duca GF, Silva MC, Hallal PC. Incapacidade funcional para atividades básicas e instrumentais da vida diária em idosos. Rev Saúde Pública. 2009;43(5):796-805.

35. Nascimento CM, Ribeiro AQ, Cotta RMM, Acurcio F, Peixoto S, Priore S, et al. Factors associated with functional ability in Brazilian elderly. Arch Gerontol Geriatr. 2012;54(2):89-94.

36. den Ouden MEM, Schuurmans MJ, Mueller-Schotte S, van der Schouw YT. Identification of high-risk individuals for the development of disability in activities of daily living. A ten-year follow-up study. Exp Gerontol. 2013;48(4):437-43.

37. Lamoureux EL, Hassell JB, Keeffe JE. The determinants of participation in activities of daily living in people with impaired vision. Am J Ophthalmol. 2004;137(2):265-70.

38. Palm H-G, Strobel J, Achatz G, von Luebken F, Friemert B. The role and interaction of visual and auditory afferents in postural stability. Gait Posture. 2009;30(3):328-33.

39. Tak E, Kuiper R, Chorus A, Hopman-Rock M. Prevention of onset and progression of basic ADL disability by physical activity in community dwelling older adults: a meta-analysis. Ageing Res Rev. 2013;12(1):329-38.

40. Balzi D, Lauretani F, Barchielli A, Ferruci L, Bandinelli S, Buitatti E, et al. Risk factors for disability in older persons over 3-year follow-up. Age Ageing. 2010;39(1):92-8.

41. Lee PP, Cunningham WE, Nakazono TT, Hays RD. Associations of eye diseases and symptoms with self-reported physical and mental health. Am J Ophthalmol. 2009;148(5):804-8.

Received: 07/09/2013

Recebido: 09/07/2013

Approved: 08/20/2014

Aprovado: 20/08/2014 